\title{
Interactive comment on "The soil fertility and leaf nutrient status in enset gardens in different altitude zones of the Gamo highlands, Ethiopia and inferences for Xanthomonas wilt prevalence" by Sabura Shara et al.
}

\section{Anonymous Referee \#1}

Received and published: 7 January 2020

Comments on MS No.: soil-2019-78 The soil fertility and leaf nutrient status in enset gardens in different altitude zones of the Gamo highlands, Ethiopia and inferences for Xanthomonas wilt prevalence Sabura Shara et al.

General The manuscript represented an interesting study about trying to determine how soil physicochemical properties in the Gamo highlands of Ethiopia influenced the development of Xanthomonas wilt of enset (EXM). The study was a survey-based investigation, where it is difficult to control all the variables to know what is exactly happening. The authors in their introduction outlines some ambitious aims from a 
survey-based study about determining optimum regimes for enset and how this may impact on EXM. The study included three different elevation categories determined by the authors of 2000-2300, 2300-2600 and 2600-3000 masl. The authors also divided enset gardens into zones based on proximity to houses, having an inner and outer garden zone and an outer cropping zone. Soil measurements were made in each of these areas for soil physiochemical properties, leaf samples made of enset plants and the assessments made on the presence or absence of EXM. The results indicated that there was little difference in soil physicochemical properties between the different elevation zones. However, differences were observed with proximity from the houses, with changes in soil chemical properties indicating greater soil fertility closer to the houses. There was some suggestion that EXW prevalence was greater at lower elevation than higher elevations. The study used visual assessments as well as historical recollections from growers. The authors concluded that EXW was lower at higher elevations. They also suggest that there is less EXW with lower soil $\mathrm{pH}$, available $\mathrm{P}, \mathrm{K}$, and $\mathrm{Ca}$. Unfortunately, there appears to be many confounding effects, which impact on the results and the conclusions made by the authors. While the authors surveyed 276 enset gardens, they based their conclusions on the results from 11 sites, those at lower elevations that had corresponding disease assessment and soil physicochemical data. The authors had suggested in their description of the sites that "organic fertilisers" were used close to the house. Would it be possible that these organic fertilisers were also sources of EXW inoculum adding to reinfection of plants? The manuscript requires major revaluation of the results before it is acceptable. Much of the physicochemical data is not significantly different from one another, there is no clear discrimination between sites and there is insufficient statistical power to agree with the conclusions made by the authors. The manuscript requires major revision to improve the clarity and conciseness of what is presented. Currently the manuscript is confusing with some terms like "inner-outer", which are difficult for the reader to follow. Furthermore, there is inconsistent use of tense, with the manuscript changing between past and present tense. This should be revised so that there is consistent 
use of past tense English. The inclusion of commas needs to be reviewed throughout the manuscript. Specific comments Abstract âÁć This is a summary of what was done and therefore should be in past tense. e.g. increase $\rightarrow$ increased, are $\rightarrow$ were etc. âÁć L28 The authors make a "throw-away" statement that, "enset gardens should be optimized in relation to agro-ecological conditions and that both elevation and soil nutrient status need to be considered......". It would be better if the authors were able to elucidate what these optimum conditions were to reduce EXW and not leave the readers wondering what these conditions were? Introduction âĂć The introduction needs to be reviewed to make it more concise with information relevant to the study. Currently there is a lot of superfluous information which does not add to the argument being developed in the manuscript. âĂć L37 Food security is a main target or is a target? âĂć L50 fibre not fiber âĂć L53 greater of higher? âÁć L55-56 How does the dense leaf canopy reduce land degradation and sequester carbon? âÁć L58 Remove Due to limited genetic research âÁć L62-64 These sentenced should be reviewed to be more concise. âĂć L72 Remove wreaking havoc âĂć L82-85 Is this sentence necessary, does it add anything to the argument being developed? âĂć L88-100 The paragraph outlining the aims and hypothesis needs to be reviewed to make both the hypothesis and aims of the study clearer for the reader. Materials and methods âĂc L110-113. Is the description of bedrock required? âÁć L153-154 Dates are confusing âÁć L159 A mixed soil sample... is a confusing sentence that requires reviewing. âĂć L202 computed not compute âĂć L211 of is repeated âÁć L212-214 It is unclear what this sentence is trying to explain. Needs revision. âÁć L211 The number of points on a positive side of the PCA diagram is $64.7 \%$, which means that $35.3 \%$ were on the negative side, which does not give a lot of confidence that there is nothing more than chance to where the points occur on the PCA biplot. The analysis and presentation of the results used should be reviewed to develop a minimum data set that discriminates between the sites and consider the use of box and whisker plots to show how much overlap and variation there is between the different categories. âĂć Fig 3 There are no obvious groupings in the PCA diagram. If 95\% confidence

Interactive comment
Printer-friendly version

Discussion paper 
intervals were placed around elevation or symptomatic gardens there would be a lot of overlap. âÁć Table 1 The table is difficult to read and understand as it is presented. Consider using horizontal lines to separate each variable. There is inconsistent placement of the soil property title either in the middle or in centre. Consider using ns to denote non-significant difference between elevation categories. This applies to all tables in the manuscript. âĂć L243 the description of the zones is very confusing. This should be revised and consistently use throughout the manuscript. âĂć Table 2 Consider using ns to denote non-significant difference between elevation categories. âÁć L258-266 This section is very confusing, and I am not sure what it is trying to explain. Is it necessary for the data presented within the manuscript? âĂć Table 3 Consider using ns to denote non-significant difference between elevation categories. Does the leaf data add much to the argument? âÁć L278-280 This sentence is unclear and requires revision âÁć L288-289 This method is not convincing for discrimination between symptomatic and asymptomatic gardens. âÁć Table 5 Consider using ns to denote non-significant difference between elevation categories. âĂć Table 6 It would appear that the entire sample size being used in this table is 11 gardens. How many were symptomatic and how many asymptomatic of EXW? 11 gardens is not a large enough sample size to be meaningful, when 276 were included in the original survey. This would mean that the results are being extrapolated from only $4 \%$ of the gardens included in the survey. âÁć Table 7 Consider using ns to denote non-significant difference between elevation categories. âĂć Discussion âĂć Review the use of tense throughout the discussion. E.g. are $\rightarrow$ were âĂć L342-343. The authors suggest that "continual application of manure and organic waste ..." is responsible for changes in soil nutrient levels. Could the organic waste also be contributing to EXW? If contaminated by-products are disposed into gardens in close proximity to houses there may be an increasing amount of inoculum that is associated with increase in nutrient levels? âÁć L352 The authors indicated that soil nutrients were greater than anticipated. The differences in soil nutrients due to proximity from the house is the main outcome from this study and could be expanded with greater analyses showing

SOILD

Interactive comment
Printer-friendly version

Discussion paper

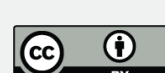


differences in nutrients due to garden zones. âĂć L356 "liming effect" or neutralising effect? âÁć L364-367 The authors suggest that foliar nutrients were excessive based on limited literature? Was there any productivity measures that would support that productivity had plateaued with the increase in leaf nutrient levels or is this purely speculative due to lack of data? Conclusion âÁc It is hard to agree with the conclusion as some of the statements are misleading, such as 276 gardens used in the study. While 276 may have been used in the study the conclusions are based on $4 \%$ of these sites, only 11 , which would appear to be insufficient to be a robust number to draw conclusion of the physicochemical properties that lead to EXW. âÁć The authors acknowledge there are many confounding effects in the study which could lead to differences in disease incidence and with only 11 sites on which the physiochemical results are based on, it does not give the reader a lot of confidence in the findings from the survey. âÁć L414 less instead of lower Suggestions âĂć There appears to be four elements to this study o Disease incidence of EXW o Nutrient status of enset gardens iĆğ With elevation íC̆ğ With distance from houses o Leaf nutrient status of enset âÁć These could be analysed separately. âĂć To me, the most interesting aspect of this study is how soil nutrients levels change with distance from the houses. This could be teased out further and reanalysed to determine groups or trends across a gradient from the house? âĂć The manuscript needs to be revised to improve clarity and conciseness throughout. âÁć More care is required in the grammar, particularly the use of past tense and the use of commas.

Please also note the supplement to this comment:

https://www.soil-discuss.net/soil-2019-78/soil-2019-78-RC1-supplement.pdf

Interactive comment on SOIL Discuss., https://doi.org/10.5194/soil-2019-78, 2019.

Printer-friendly version

Discussion paper

Interactive

comment

Discussion pape 